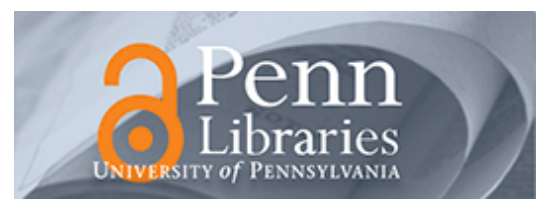

University of Pennsylvania

ScholarlyCommons

\title{
Evidence-Based Medicine and the Law: The Courts Confront Clinical Practice Guidelines
}

Arnold J. Rosoff

University of Pennsylvania

Follow this and additional works at: https://repository.upenn.edu/lgst_papers

Part of the Business Commons, and the Law Commons

\section{Recommended Citation}

Rosoff, A. J. (2001). Evidence-Based Medicine and the Law: The Courts Confront Clinical Practice Guidelines. Journal of Health Politics, Policy and Law, 26 (2), 327-368. http://dx.doi.org/10.1215/ 03616878-26-2-327

This paper is posted at ScholarlyCommons. https://repository.upenn.edu/lgst_papers/12

For more information, please contact repository@pobox.upenn.edu. 


\title{
Evidence-Based Medicine and the Law: The Courts Confront Clinical Practice Guidelines
}

\author{
Abstract \\ This article examines how courts are likely to apply evidence-based medicine, and particularly clinical \\ practice guidelines (CPGs), in healthcare litigation involving quality-of-care and entitlement-to-benefits \\ (coverage) claims. Exploring the "politics" of the current situation, it observes that, just as clinicians have \\ been reluctant to use CPGs in practice, courts have been, and likely will continue to be, slow to apply them \\ in deciding cases., The article analyzes extant and proposed statutory approaches to legitimizing and \\ promoting courts' use of CPGs. It concludes by renewing the author's earlier and controversial proposal to \\ establish a voluntary federal program for certifying guidelines and directing courts to give certified CPGs \\ greater weight in healthcare litigation. \\ Disciplines \\ Business | Law
}




\title{
Evidence-Based Medicine And the Law: The Courts Confront Clinical Practice Guidelines
}

\author{
Arnold J. Rosoff \\ University of Pennsylvania
}

\begin{abstract}
This article examines how courts are likely to apply evidence-based medicine, and particularly clinical practice guidelines (CPGs), in healthcare litigation involving quality-of-care and entitlement-to-benefits (coverage) claims. Exploring the "politics" of the current situation, it observes that, just as clinicians have been reluctant to use CPGs in practice, courts have been, and likely will continue to be, slow to apply them in deciding cases., The article analyzes extant and proposed statutory approaches to legitimizing and promoting courts' use of CPGs. It concludes by renewing the author's earlier and controversial proposal to establish a voluntary federal program for certifying guidelines and directing courts to give certified CPGs greater weight in healthcare litigation.
\end{abstract}

\section{The Advent of Evidence-Based Medicine}

The past few decades have seen tremendous and exciting strides in the development of evidence-based medicine (EBM), defined as the conscientious, explicit, and judicious use of current best evidence in making decisions about the care of individual patients (see Cynthia D. Mulrow and Kathleen N. Lohr in this issue). ${ }^{1}$ Medicine, long recognized as a subtle admixture of science and art, has moved notably in the direction of an exact science as new tools and techniques have been developed to help practitioners of "the healing arts" understand better what works in the treatment of patients. This dramatic expansion of medical knowledge, and of the ways by which medical knowledge is advanced, is changing the face of medical practice.

1. Mulrow and Lohr cite Sackett et al. 1997, as the source of this definition.

Journal of Health Politics, Policy and Law, Vol. 26, No. 2, April 2001. Copyright ( 2001 by Duke University Press. 
A key aspect of this change has been the development of outcomes research, for systematic and large-scale study of the effects different diagnostic tools or therapies have when applied to large numbers of patients (see U.S. Congress 1994; Roper et al. 1988; Havighurst 1990). Facilitated by the widespread use of computers to record and analyze medical data and the standardization of encounter and treatment data, outcomes research is increasingly making it possible to know more precisely and certainly what is, and is not, effective therapy.

Many in the health care community have welcomed this advance of knowledge, but some see a potential downside for professional autonomy. When more is known about the "right" way to treat a particular condition, there is less latitude for individual judgment. Clinicians, historically accorded wide latitude for the exercise of personal discretion in choosing treatments for their patients, now feel increasing pressure to conform to established norms of treatment. Much of that pressure comes from managed care organizations (MCOs) and health plans, both private and governmental, all pursuing an agenda of aggressive cost containment. Moreover, in an environment supportive of EBM, a clinician might more readily be held accountable for a poor outcome if it can be attributed to deviation from an EBM-based prescribed treatment approach. For this reason, EBM is seen by some as packing a one-two punch: erosion of autonomy going into a treatment situation accompanied by greater risk of liability after the fact. It's no wonder, then, that some parts of the medical community view EBM as a mixed blessing.

A major way that EBM has impacted medical practice has been through the development, dissemination, and use of clinical practice guidelines (CPGs). The Institute of Medicine's widely cited 1990 report defines CPGs as "systematically developed statements to assist practitioner and patient decisions about appropriate health care for specific clinical circumstances" (Field and Lohr 1990). CPGs can be used to guide practitioners in undertaking treatment of various kinds of conditions and to help third-party payers, regulatory bodies, and courts determine whether care given in a particular instance was adequate and appropriate. Thus CPGs have relevance both for the practice of medicine by physicians and for the regulation of that practice by others.

A brief word about terminology: Because CPGs are the most common practical embodiment of EBM, the terms "clinical practice guidelines" and "evidence-based medicine" and their acronyms have often been used interchangeably, or nearly so. Daniel W. Shuman's essay in this symposium issue treats them this way; this article will too. It should be under- 
stood, however, that they are distinct terms and can be used in contexts where they are not interchangeable. EBM can show up in forms other than CPGs - for example, in journal articles, unpublished studies, and expert testimony. Conversely, CPGs are not necessarily based upon EBM - although the vast majority of the CPGs being generated nowadays are, or at least purport to be. Cynthia Mulrow and Kathleen Lohr's essay recognizes that guidelines generated primarily through a professional consensus process - the traditional approach - may differ from those based more directly on hard, empirical evidence-the EBM approach. This last point is especially important, because courts, in deciding what weight to accord to CPGs, may find it useful, even necessary, to distinguish between those that are based on EBM and those that are not.

Building on professional reservations about EBM generally, growth in the development and use of CPGs has fueled concern in some quarters about their implications for medical practice. Some decry the spread of CPGs as the advent of "cookbook medicine," having the potential to turn doctors into automatons and lower the quality of health care by subordinating and subverting professional skill and judgment. While many of the changes to be expected from EBM and CPGs are positive and should be welcomed and facilitated, the political climate for their acceptance, discussed below, is far from assured.

For the balance of this section, this essay lays a foundation by discussing in general terms how courts might benefit from the use of EBM, especially in the form of clinical practice guidelines, and by examining, again in general terms, why and how courts might have difficulty in adopting and using CPGs. In the second section, the essay examines various ways courts might employ CPGs in handling quality-of-care and entitlement-to-benefits cases. Courts' actual experience with litigation involving CPGs is highlighted, as is emerging legislation that defines how, and by whom, CPGs may be used in litigation. A third section explores the "politics" of EBM and CPGs, considering how political and cultural forces in the health care, legal, and public policy communities may bear upon the rules legislatures and courts apply to govern the use of this type of evidence. Finally, the essay concludes with a proposal I put forward some five years ago (Rosoff 1995) for the development of a governmental certification program for CPGs. The essential notion is that, in the face of multiple, competing guidelines for treating particular conditions, courts could benefit greatly from some mechanism, presumably governmental, that would help them sort credible and authoritative guidelines 
from those not so deserving of the courts' acceptance. While numerous factors, some of them "political," in different meanings of that term, cut against the establishment of a certification program, I continue to believe the idea has merit and deserves further consideration.

\section{The Law's Acceptance of Evidence-Based} Medicine

In addition to professional reactions to EBM, how the law regards and treats EBM will also greatly affect the pace and nature of its acceptance. There are troubling indications that the courts haven't figured out yet how to deal with medical evidence in a variety of contexts. A great deal has been written about the distorting effects of "junk science" in litigation concerning silicon breast implants, various drugs and medical devices, such as Bendectin and IUDs, toxic torts, and other controversies involving scientific evidence. Popular books of the past few years - such as David Faigman's Legal Alchemy: The Use and Misuse of Science in the Law (1999) and Marcia Angell's Science on Trial: The Clash of Medical Evidence and the Law in the Breast Implant Case (1997) — raise disturbing doubts about how often the courts can "get it right" when dealing with evidence of this nature. The great promise of EBM to improve the quality of care, help contain health care costs, reduce disputes about coverage under health plans, and ease the financial and other burdens of medical malpractice litigation on the health care system may be compromised if the law is unsure or confused about how to deal with EBM.

How, then, can we move most effectively toward the adoption of desirable legal rules and procedures for dealing with evidence-based medicine? The traditional process of generating legal doctrine in a new area through litigation on an ad hoc, state-by-state basis, as cases happen to come up, is too haphazard and slow to be adequate for a matter as important, volatile, and fast-moving as the adoption and use of EBM. As noted above, this essay considers some approaches that have been tried in an effort to accelerate EBM's assimilation into the law and, toward that same end, offers the author's proposal for certification of clinical practice guidelines.

\section{The Uses of Medical Evidence in the Courts}

In general, people are enthusiastic about the prospect of developing better tools that will enable them to do their jobs more efficiently and effec- 
tively. When faced with the reality of new tools, however, this enthusiasm often is diminished by the challenges of improving skill levels. Once a new tool is mastered, the investment in gearing up to use it may "pay for itself" many times over, either by saving future time and effort or by making possible a better product or service. In the short run, though, adoption of new approaches can generate more cost than benefit. This may well be the case with the emerging use of EBM by the courts. EBM applications may ultimately make it much easier for courts to resolve health care disputes; but, in the short run, the courts will have to learn new principles and develop new rules for applying them in the litigation context. There will undoubtedly be challenges to those rules. An important objective of the symposium that spawned these essays was to help assure that the legal system's balance sheet on EBM comes up positive at the earliest time possible.

To discuss how the legal system will treat new forms of medical evidence, it is necessary to recognize that such evidence is used by the courts in a number of different contexts. Within the frame of the present discussion, two main categories of use are relevant: challenges regarding the quality of care (the principal subject of medical malpractice litigation) and challenges regarding the determination of what benefits are covered under a health plan in a given instance. Federal courts have struggled for several years to sort out these two classes of issues in cases involving the scope of federal preemption under ERISA, the Employee Retirement Income Security Act of 1974 (29 United States Code 1001, et seq.) (see Dukes v. U.S. Healthcare, 57 F.3d 350 [3d Cir. 1995]; Mariner 1996, 2000). Under managed care, these two sets of issues, though historically separate, increasingly tend to be intertwined. With growing frequency, suits are filed claiming that the quality of care was inadequate because benefits owed under the plaintiff's health plan were withheld, either with or without the plaintiff's knowledge at the time. Both quality-of-care and coverage cases involve common issues that are typically addressed through the testimony of medical expert witnesses. The main issues commonly calling for expert testimony are: (1) the applicable standard of care, (2) causation (the connection between the alleged wrongful conduct and the harm suffered by the plaintiff), and (3) the assessment of damages, which often involves (4) medical prognosis.

The type of issue involved dictates the nature and scope of the expert witness's input. The last three of these issues-causation, assessment of damages, and prognosis - usually require the expert witness to apply his 
or her expertise directly to the question at hand. ${ }^{2}$ The first of the four issues, the standard of care, is different, however. On this point, an expert is supposed to testify not as to what she or he thinks is the proper way to treat the case at hand but, rather, as to what others in the profession commonly would do in such a situation. The expert's testimony is focused this way because courts usually measure the adequacy of a patient's treatment by its conformity to standard practice in the relevant medical community, the so-called professional community standard. Thus, in this context - different, perhaps, from all others in which medical experts are called to testify - the expert's contribution is not his own scientific judgment or expertise about how best to handle a clinical situation but, rather, his or her knowledge of how professional peers commonly handle similar situations. This difference in the treatment of standard-of-care issues is important to the present discussion because, as explained below, a court uses a CPG to establish the legal standard of care, obviating the need for expert testimony on that point. By contrast, even where a CPG contains information relevant to causation, assessment of damages, or prognosis, it is hard to see how a court could make use of this information without the accompanying testimony of a medical expert witness. For this reason, and because the main object of CPGs is to set a standard of care, the present discussion addresses only those situations where CPGs are used to help determine the legal standard of care to be applied in the case being litigated. Belying the assertion just made about what the main object of CPGs is, for reasons of professional politics and in contemplation of litigation, guidelines developers routinely disclaim that their recommendations are "standard-setting." Despite these protestations, it remains an open question whether, and to what extent, courts will treat CPGs as setting the legally required standard of care.

\section{Problems with New Tools}

Will the explosion of medical evidence and CPGs be a help or a hindrance to the courts? On the one hand, better evidence might make it easier for courts to reach accurate determinations in a difficult technical area. On the other hand, the profusion of evidence, seemingly or actually

2. For example, where the issue is causation, the question might be put as follows: "Doctor, in your expert opinion, based upon your knowledge and personal experience, do you believe that the defendant's acts (or omissions) caused the plaintiff's injury?" Similar examples could be offered involving assessment of damages ["Doctor, how serious is the patient's injury? In your view, is this a case of "total disability?"] and prognosis ["Doctor, in your opinion, will the patient-plaintiff ever again be able to drive a truck?]. 
inconsistent (e.g., conflicting clinical practice guidelines), could confuse more than clarify.

To illustrate with an example, imagine that a forty-five-year-old female HMO member loses a breast to cancer, which, she claims, could have been treated successfully if caught earlier by more frequent mammography screening. The HMO screened once every two years, following the guidelines of the National Cancer Institute (NCI) for women in her age and risk category. The patient-plaintiff rests her case on a contrary guideline, issued by the American Cancer Society (ACS), which calls for screening once a year for women in that category. The jury must decide whether the doctor and HMO met the standard of adequate care by screening on the less frequent schedule. Traditionally, before CPGs were such a part of the picture, the parties in a malpractice case would address this issue by having medical experts testify on each side as to the professional community standard - the classic "battle of the experts." Might the contest be raised now to a higher level, with the guideline of one respected professional group pitted against that of another? Will we now see a "battle of the super-experts?" Clark Havighurst (1991: 95), in his seminal early exploration of the use of guidelines, observed that "practice guidelines may only occasionally resolve a dispute crucial in the litigation of an actual malpractice claim." But, now that the guidelines movement has gathered another decade's worth of momentum, that may be changing. With CPGs routinely playing a central role in the determination of what care patients receive, it is easy to envision them assuming a more prominent role in fixing the legal standard for measuring the adequacy of that care-in other words, serving the evidentiary function traditionally served by live experts.

If CPGs do come to play a greater role in medical malpractice and related cases, might a court allow evidence and/or argument to the point that one guideline-generating organization was entitled to more respect than the other or that one set of guidelines was more credible because better supported by the underlying data or by a more robust methodology for outcomes research, possibly including cost-effectiveness analysis (CEA) (see Peter D. Jacobson and Matthew L. Kanna in this issue)? Might the court allow the parties to lead the jury through the mechanics and nuances of EBM research and guideline generation? Might one party try to show that, whereas its guideline was based on solid, up-to-date empirical data, its opponent's older guideline was developed through a more subjective, consensus-based process and, thus, was less valid? Such evidence, while it might fascinate a jury, would likely have great poten- 
tial to confuse it. Under the principle of Daubert v. Merrell Dow Pharmaceuticals [509 U.S. 579 (1993)], as described in Shuman's article in this issue, a trial judge is required to prescreen scientific evidence and admit only that which is likely to inform the jury and not confound it. In pursuing this obligation, might the judge bar this entire line of inquiry? Might she simply make an initial determination as to whether each of the proffered CPGs was authoritative enough to be admitted and then let them go to the jury on equal footing even though she believed one to be notably more sound-i.e., better conceived or based on stronger science-or more reputationally authoritative than the other? It is clear that the court's job in managing health care litigation may be significantly more complex in the face of the better knowledge and evidence that EBM makes possible than it would have been previously in "less enlightened" times. (It should be noted that the Daubert ruling applies only in cases controlled by the Federal Rules of Civil Procedure and those in states that have adopted the principle of Daubert.)

Assuming, for the sake of argument, that a savvy trial judge understands enough about CPGs to make wise rulings about how they should be handled as evidence, there still is likely to be controversy around such rulings until they are validated on appeal. Novel procedural rulings, such as those involving the admissibility and significance of new kinds of evidence, routinely invite challenges. (As has happened before in health care, and other fields, courts may be hindered in reaching important substantive issues because they first have to formulate new definitional and procedural rules and have them tested and approved. Consider, for example, the protracted haranguing over the use and validity of DNA evidence in the criminal trial of O. J. Simpson.) An example of this phenomenon, addressed in the Shuman essay, is the treatment of expert testimony in litigation involving medical and scientific matters (e.g., products liability, toxic tort, etc.). Other examples in the health care field include cases involving contractual arbitration in health care (Madden v. Kaiser Foundation Hospitals, 552 P.2d 1178 [Cal. 1976]; Rosoff 1986) and the use of pretrial screening panels for medical malpractice cases (Macchiaroli 1990; Carlin 1980; Institute of Medicine 1978). Issues will inevitably arise as courts pick their way through the question of how to handle CPGs as evidence. Challenges will address not just the admissibility of and weight to be accorded to CPGs but also whether the use of CPGs is allowed to both plaintiffs and defendants on an equal basis, an issue discussed below. 


\section{Clinical Practice Guidelines in the Courts}

U.S. courts have only just begun to figure out how to deal with clinical practice guidelines (CPGs). To date, most of the litigation about CPGs has involved claims of medical malpractice. Going forward, it is likely that CPGs will also figure prominently in suits involving coverage decisions made under health plans. The relatively few courts that have dealt with CPGs have varied widely in their treatment as evidence. In some instances, CPGs have simply been deemed inadmissible. For example, a 1995 Maryland statute enacted to encourage guidelines development provided that CPGs developed under the program it established could not be used in litigation (Md. Code Ann. [Health-Gen.] Section 19-606), a restriction that has since been removed from the legislation. In future cases, pursuant to state legislation fostering CPG development and use, some courts will admit them only for use by the defense. Even where they can be introduced by both parties to a litigation, there is a range of alternatives as to how much weight they will be given. Certainly, it will be some time before there are settled conventions for the use of CPGs and for instructing juries on the matter.

\section{The Importance of Federal Law}

The analysis in the following section builds upon state law foundations and assumes the role of CPGs will be determined as a matter of state law. Medical malpractice has historically been a matter of state law and not subject to federal control. For that reason, federal courts have rarely been involved, except in diversity of citizenship cases, that is, where a citizen of one state sues a citizen of another state and the amount in controversy exceeds a statutory threshold, currently $\$ 75,000$. In diversity cases, the U.S. Supreme Court's ruling in Erie R. R. Co. v. Tompkins (304 U.S. 64 [1938]) requires federal courts to follow the applicable state law, if there is any. In cases before them on whatever jurisdictional ground, however, federal courts largely apply their own rules of procedure. Thus, to the extent that the treatment of CPGs is regarded as an evidentiary (procedural) matter, federal courts are free to fashion rules regarding their admissibility, rules of application, weight, and so on. If, on the other hand, the use of CPGs is deemed to be substantive rather than procedural, federal courts would be bound to follow state law or, in the absence of controlling state law, to treat CPGs as they predict courts in the relevant state would if the same case were tried there. In this author's pro- 
posal for a federal program to certify CPGs, the assumption that state law would control is, for the most part, set aside.

There is ample precedent for extending federal control beyond its traditional limits through "carrot and stick" initiatives, whereby adherence to federal law, or federal standards for state law, is the statutory quid pro quo for receiving federal funds. The federal health care programs, Medicare and Medicaid, are examples of this in general. As a more concrete example, hospitals that participate in Medicare and operate an emergency department are required by the Emergency Medical Treatment and Active Labor Act (EMTALA) (42 United States Code Annotated, Section 1395dd [1985]) to provide initial assessment, advice, and treatment until the patient's condition is "stabilized," as defined in the legislation. The obligation applies whether or not the individual in question is covered under the federal program. Presumably, something similar might be undertaken in the present instance, if adequate political support for a federal CPG program could be developed. Note, however, that such a change would raise significant issues of statutory and constitutional law. The division of authority and responsibility for financing, providing, and regulating health care involves complex questions of states' rights and separation of powers. It also implicates important federal statutes, such as the McCarran-Ferguson Act (15 United States Code 1011, et seq. [1945]) and the Employee Retirement Income Security Act (ERISA) (29 United States Code 1001, et seq. [1974]). Further consideration of the role of federal law is reserved for the later discussion of the proposed certification program; the rest of this section assumes that state law controls.

\section{Admissibility and Weight Given to Clinical Practice Guidelines}

There are various approaches state courts could take with regard to clinical practice guidelines in the context of medical malpractice litigation. The treatment of CPGs obviously will depend on the underlying legal terrain in each state. There is substantial commonality among the states with regard to their definitions of medical negligence and the evidentiary requirements for proving and defending against malpractice claims. However, there are differences among the states that, while subtle and occasionally largely semantic, may yet be quite significant. The possibilities set forth below are not mutually exclusive; a court could adopt a treatment of CPGs that combines elements of two or more of them. 
As Evidence of Customary Practice. A core principle in medical malpractice litigation followed in most, but not all, cases is that the legal standard of care is set to customary practice in the relevant medical community, the so-called professional community standard. Thus, in most jurisdictions, under most circumstances, adherence to prevalent professional standards is an adequate defense to a claim of medical negligence. The most obvious possibility for the use of CPGs, then, is that a court could look to them as evidence of what is customary practice in the medical profession. A physician who practiced in conformity with a CPG would be shielded from liability to the same extent as one who could establish that she or he followed professional custom. Conversely, a physician's failure to conform to a recognized guideline could raise an inference that she or he did not perform up to the required standard; at the least, it would obligate the physician to explain why the CPG was not followed.

The main problem with treating CPGs as evidence of professional custom, however, is that in the case of a newly developed guideline, the treatment approach it calls for may differ, perhaps substantially, from prevailing practice in the profession. This is particularly likely in the case of cost-reducing guidelines that have evolved from EBM studies that conclude that the conventional practice "overtreats" the patient and wastes resources without yielding discernible or sufficient benefit in terms of better treatment outcomes. As noted above, some CPGs are developed through a consensus process, in which the treatment recommendations are an amalgam of contemporary professional belief and practice. Other CPGs are generated through a more scientific, EBMoriented process, in which the foundation is rigorous analysis of empirical outcomes data rather than the cumulated beliefs of practitioners. If admitted as evidence in malpractice litigation, guidelines formulated in the first way described would generally serve much the same function as medical expert testimony as to customary practice. The latter type of CPGs, at least when first disseminated to the medical community, are much less likely to reflect current professional practice. Such guidelines are commonly employed in an attempt to change physician practices in order to make them more cost-effective. As a new guideline gains more currency and more adherents, it will increasingly become synonymous with customary practice. In the short run, however, it is likely to be just the opposite, a statement of what the profession at large currently does not do. Thus, so long as courts use "customary practice" to set the legal standard for acceptable practice, EBM-derived CPGs will be of limited or questionable utility in the legal system. 
It is instructive to note that CPGs developed from EBM rather than through a professional consensus process differ in this regard from the more traditional Medicare utilization review (UR) protocols, which were statutorily required to be based upon "professionally developed norms of care, diagnosis, and treatment based upon typical patterns of practice" (Public Law 92-603, Section 249f, 42 United States Code, Section 1301). The requirement that Medicare's UR protocols be derived from customary professional practice, as revealed in Medicare claims data, undoubtedly was driven by political pressure from professional interests. Professors William Trail and Brad Allen (1995-96: 236-237) draw a different distinction between what they call "medical practice guidelines" and UR guidelines. They characterize the latter, pejoratively, as being concerned only with cost containment and thus having no relevance to quality of care debates. Havighurst (1990: 778, n.3, citing Lewin and Erickson 1989: 3 ) acknowledges a similar distinction between "pathway" (quality) guidelines and "boundary" (payment) guidelines: "Boundary guidelines are used by payers to define the range of practice options within which physicians could act without incurring financial or other sanctions. Pathway guidelines are employed primarily by providers and serve as a beacon for clinical practice and a standard around which practice patterns should converge."

As Evidence of a "Respectable Minority" Approach. A number of states recognize it as a malpractice defense that the defendant acted in accordance with the custom of at least a "respectable minority," or recognized subgroup, of the relevant profession, even though his or her actions were at odds with mainstream professional practice (Furrow et al. 1997: 198-202). In such a state, a relatively new guideline, although it has not yet been adopted widely enough to be reflective of "mainstream" practice, might be sufficiently well accepted to qualify under the "respectable minority" doctrine. Use of this defense would seem apt where the issuer of the guideline was a well-established professional society, such as the American College of Obstetrics and Gynecology (ACOG). However, if the guideline were the product of an upstart or renegade group, or perhaps a team of commercial consultants working under contract with an MCO with the transparent objective of devising ways to reduce costs, it might be rejected as not representing the position of a "respectable minority" of the profession.

As Evidence of "Reasonable Prudence." Adherence to a legitimate CPG could be treated by the court as evidence of a physician's "reasonable prudence," even if it were not established that a substantial number of 
physicians had yet applied the guideline's approach in clinical practice. Some courts define the physician's legal obligation of due care in terms of reasonable prudence rather than adherence to professional custom. This was the approach taken in the Washington Supreme Court's controversial decision in Helling v. Carey (519 P.2d 981 [Wash. 1974]), which held that reasonable prudence, not customary professional practice, is what should be determinative in setting legal standards for medical care. In so holding, the Helling court cited Judge Learned Hand's oft-quoted declaration in The T. J. Hooper (60 F.2d 737, 740 [2d Cir. 1932]) that "in most cases reasonable prudence is in fact common prudence; but strictly it is never its measure." A court following the Helling rationale could choose to regard a physician's reasoned compliance with a legitimately developed CPG as meeting the standard of reasonable prudence.

As Evidence of “Acceptable Practice.” Regardless of the number of practitioners actually following a particular treatment modality at the time, a court could choose to regard it as "acceptable practice" within the medical community if sanctioned by an appropriate and credible CPG. This approach, suggested some twenty-five years ago by Professor Joseph King (1975: 1236), would be very similar to direct application of the CPG as the applicable legal standard, which is discussed next. It is also similar in concept to the "respectable minority" doctrine, discussed above. That is, if the medical community respects a practice as having been carefully considered and found acceptable by a reputable subset of the profession, it would not be regarded as improper practice, even if relatively few clinicians had actually adopted it as of the time in question. The key to the court's recognition of the CPG as the legal standard would, in any case, be the medical profession's acceptance of the CPG as authoritative. As in the case of the respectable minority doctrine, acceptance would be affected by the reputation and influence of the body(ies) developing, endorsing, and/or adopting the CPG.

As the Legal Standard of Care (Direct Application). The most straightforward and complete acceptance of a CPG, of course, would be for a court simply to treat it as setting the applicable legal standard without going through any intermediate steps based upon professional acceptance or customary usage. Giving such direct application to CPGs would be a substantial departure from existing law and would, presumably, require legislative action (ibid.: 1235). While this is a simple route conceptually, it would be a major step politically, since detaching standard setting from professional consensus has far-reaching implications. 
If a CPG were to be adopted as the legal standard, questions remain as to how that standard would be applied. Regarding the weight to be given to it, the most extreme approach would be to treat it as a per se standard. In other words, it would be conclusively, or irrebuttably, presumed that the physician was negligent if she or he didn't follow the standard and, conversely, that the care was reasonable if she or he did follow it. This is essentially the approach specified in Minnesota's practice guidelines legislation, discussed below (Minnesota Statutes, Section 62J.34[3], [1992]). A less prescriptive approach would be to treat compliance with a relevant guideline as raising a rebuttable presumption that the physician acted correctly; similarly, noncompliance would raise a rebuttable presumption that the physician acted negligently. Whichever party asserted the guideline, the opposing party could attempt to counter this presumption by appropriate evidence. This was the approach contemplated in the Health Equity and Access Reform Today (HEART) bill, proposed by Senator John Chafee (R-R.I.) and others in 1993. (S. 1770, 4025, 103d Cong., 1st sess.). Under HEART, adherence to state-developed guidelines which had been certified by the secretary of Health and Human Services would raise a rebuttable presumption of appropriate care that would be overcome only by "clear and convincing evidence," a stricter than normal evidentiary standard favoring the party complying with the guideline. The Chafee bill is significant here because, in the part just discussed, it bears a close resemblance to the proposal put forward below for a CPG certification program.

Another dimension to the adoption of a CPG as the legal standard would be whether that standard is available for use by both the plaintiff and the defendant. Recent evolution of the use of CPGs as a legal standard has favored their use only as a defense by the health care provider. Whether CPGs should be applied in such an asymmetrical manner is considered below.

Directly applying CPGs as the legal standard for medical care is an extreme recognition that seems inappropriate and unlikely at this relatively early stage of their development. Public, professional, and judicial confidence in CPGs would have to be greater than it is currently for them to be accorded this much weight by the legal system. Before such confidence could be gained, many more issues about CPGs, their auspice, development, and so on, would have to be addressed and satisfactorily resolved. Because these conditions have not been met, the American Medical Association opposes, for the present at least, direct adoption of CPGs as a legal standard and urges instead that they be used only as evi- 
dence of the customarily observed professional standard of practice and that their degree of authority be dependent upon the degree of their acceptance among medical practitioners (American Medical Association 1993: 58; Hirshfeld 1993: 323). As Richard F. Corlin, M.D., testified on behalf of the AMA (1993: 58): "At the present time, insufficient evidence exists to show that clinical practice guidelines can be developed in a manner specific enough to be introduced as an affirmative defense in medical liability litigation." It is notable that the AMA's reservation about CPGs was stated even in the context of their defensive use.

\section{Courts' Experience with Clinical Practice Guidelines}

To date, there has been relatively little litigation using CPGs. Andrew Hyams, David Shapiro, and Troyen Brennan (1996) did an extensive computerized legal search covering the period from January of 1980 through May of 1994 and turned up only thirty-seven cases involving CPGs. This is not to say, however, that CPGs do not figure importantly in malpractice litigation. A survey of medical malpractice attorneys conducted by Hyams, Shapiro, and Brennan (1996: 292) revealed that about half of them were aware of practice guidelines and a substantial number considered guidelines in deciding whether or not to take on malpractice cases. Guidelines also influenced settlement negotiations in many instances. Thus prelitigation effects are an important part of the picture, although such effects do not show up in studies of reported cases.

In principle, although not necessarily in practice, guidelines can be used in litigation by both patient-plaintiffs and physician-defendants. A patient-plaintiff can use a CPG for inculpatory (blame-placing, or "sword") purposes by establishing that there was an applicable guideline that the defendant should have followed but did not. Conversely, a defendant can use a CPG for exculpatory (blame-relieving, or "shield") purposes by showing that he or she acted in conformity with an applicable guideline. In either case, the party asserting the guideline is asking the court to accept it as proof that the physician either did (shield use) or did not (sword use) meet the legally required standard of care.

The studies by Hyams, Shapiro, and Brennan of reported lawsuits have shown that CPGs are much more commonly used by plaintiffs and, moreover, that plaintiffs have a notably higher rate of success in litigation associated with such use. Reports of the lopsided use and effectiveness of CPGs (Felsenthal 1994) raised alarm within the medical commu- 
nity and reinforced other concerns, noted above, about EBM, including CPGs. To avoid chilling the progress of CPG development and adoption, professional interests and legislators have joined in a politics of accommodation that threatens to turn CPG use in courts into a "one-way street" (Hyams, Shapiro, and Brennan 1996: 304). The legitimacy and advisability of this development is addressed in the following section.

\section{Who Can Use Guidelines and for What Purpose?}

An important question that clouds the broader consideration of how CPGs should be treated in the courts is whether both plaintiffs and defendants should be allowed to use CPGs in litigation. Responding to the concerns discussed in the preceding section about CPGs being used more often and more effectively by plaintiffs, many proponents of CPGs have successfully lobbied for laws allowing only "shield" use of guidelines by defendants, sometimes referred to as a "one-way street" approach. The earliest, and still the principal, example of this uneven application is Maine's 1990 Medical Malpractice Demonstration Project (24 Maine Revised Statutes Annotated, Sections 2971-2978), which set up a fiveyear experiment, starting in 1992 and subsequently renewed for another five years in 1997, authorizing physicians (and their employers) to use guidelines developed through the project as a shield while prohibiting their sword use by patient-plaintiffs (see Schanz 1993; General Accounting Office 1993). Although this was the clear intent of the legislation, some have questioned whether it will have this effect in practice. A representative of the Maine Trial Lawyers Association (MTLA), which opposed the experiment before the legislature, has predicted that Maine courts - driven by constitutional due process and equal protection concerns - will ultimately allow both sides to introduce the guidelines in malpractice litigation (MTLA 1994: 754).

Some other states, notably Minnesota, have followed Maine's lead by adopting laws providing for only defensive use of practice guidelines (Minnesota Statutes, Section 62J.34[3][a] [1992]). This was also the approach of the Clinton administration's ill-fated Health Security Act proposal (H.R. 4469, 103d Cong., 2d sess., 1994: 441) and several other federal health care reform initiatives of the mid-1990s. Florida initiated a guidelines demonstration project in 1996, roughly similar to that of Maine but limited to cesarean deliveries, the most common surgical procedure in Florida hospitals (Florida Statutes, Section 408.02[9]). The Florida legislation contemplates use of guidelines as a liability shield, although it doesn't expressly limit their use to the defense. 
What has been the experience under these one-sided statutory schemes? Maine, with the oldest, most fully articulated program, would seem the most likely to have data to evaluate. In fact, there apparently has been only one use of the guidelines in a litigation context since Maine's experiment began in January of 1992. T. Rosser Matthews (1999: 300) observes that there was only one claim on record (as of December 1997) in which a physician asserted compliance with an approved guideline as an affirmative defense. Earlier reports of the Maine experiment have noted no constitutional challenges to the program's asymmetry (MTLA 1994: 753; General Accounting Office 1993: 19).

The paucity of malpractice litigation in Maine since the institution of the state's CPG experiment is partly due to the fact that the same law that authorized it also mandated prelitigation screening and mediation panels. These panels are charged to "identify claims of professional negligence that merit compensation and to encourage early resolution of these claims prior to commencement of a lawsuit" and "encourage early withdrawal or dismissal of nonmeritorious claims" (24 Maine Revised Statutes Annotated, Section 2851[1][a][b]). In performing its review, a screening panel is required to determine if "the defendant complied with an applicable parameter or protocol establishing the applicable standard of care" (ibid., Section 2855[1][a-1]).

Other evidence of the program's impact, such as a reduction of health care costs reflecting a lesser incidence of defensive medical practice, is also inconclusive, although it has been reported that doctors are performing fewer medical procedures prompted by legal considerations (MTLA 1994: 753). Likewise, the effect of the demonstration project on malpractice insurance premiums is uncertain. In 1994 the state's superintendent of insurance estimated that the experiment would yield a 0.5 percent savings in malpractice premiums (ibid.). More recently, however, the Bureau of Insurance reported that it cannot distinguish the impact of the experiment from other factors affecting medical professional liability claim costs and premiums (Matthews 1999: 300). The experiment was extended for another five years in 1997. However, in a small state like Maine, with relatively few malpractice suits, it may take longer than that to gain enough data to fully assess the program's effectiveness. In fact, the program may never be able to prove a reduction in the cost of medical care or of malpractice litigation (MTLA 1994: 754). Doctors in the four specialties originally targeted by the legislation - anesthesiology, emergency medicine, obstetrics and gynecology, and radiology - have been supportive of the project. However, other specialties did not take advantage of a 1993 legislative amendment to expand the project into 
their areas of practice (Chapter 477 of Maine Revised Statutes Annotated; MTLA 1994: 753).

This uneven application of CPGs has come about as a political barter, with legislators assuring physicians, in effect, that if they will support the development and adoption of guidelines, those guidelines cannot be turned against them in litigation (General Accounting Office 1993: 26-27). It is not clear that such protection is needed to jumpstart the guidelines movement. The potential benefits of and practical pressures for expanded use of CPGs are so strong and widespread, as are the pressures for managed care generally, that physicians might not be able to resist them in any event. Still, political deals were struck to foster the development of guidelines meant to discourage the defensive practice of medicine (Shuman 1997: 105). Thus, in a number of states that have legislation providing for CPGs, the laws are structured largely for the protection of providers.

Should the use of CPGs be a "two-way street," with this form of evidence available equally to both parties? The answer would appear clearly to be "yes." In virtually every other context evidence that is seen as legitimate and admissible by the court is allowed on an equal basis to both parties. Giving providers assurance that guidelines can be used only in their favor may be an important step toward gaining their support; but allowing such one-sided use of evidence in a court of law raises disturbing questions of fairness and of validity under the U.S. Constitution's Fifth and Fourteenth Amendments' due process and equal protection mandates, and under state constitutional principles as well (see Begel 1995: 93-97; Mehlman 1990: 378; but see Hirshfeld 1991: 2889-2890).

\section{The Problem of Conflicting Guidelines}

Supporting the early enthusiasm for CPGs was the notion that they would ease the job of the courts in deciding medical malpractice cases (Brennan 1991: 73). As mentioned above, getting at "the truth" in these cases has traditionally involved a "battle of the experts," with professionals on both sides offering opposing testimony as to the applicable standard of care and the lay jury left scratching its collective head over which of the two (or more) experts to believe. If there were a definitive guideline, some theorists reasoned, the courts could simply treat that guideline as setting the applicable standard of care. Even with the CPG supplying the legal standard, there would still be challenging work for the jury. For instance, there could be difficult factual questions as to 
(a) whether the CPG proffered was appropriate to the case being litigated; (b) if so, whether the defendant provider had complied adequately with the CPG; (c) whether, if there was noncompliance with an applicable guideline, the plaintiff's harm resulted from that noncompliance; and so forth. Nonetheless, having a single, definitive point of reference to fix the appropriate standard of care would greatly simplify the judicial process, largely by avoiding the traditional battle of the experts on that critical issue.

Having a single authoritative guideline for each medical condition is not likely to be, however. For one thing, achieving such unanimity would require designating some entity, presumably a governmental agency, as the sole arbiter of what is acceptable medical practice. That is practically and politically inconceivable; the commitment to pluralism and competition is too deeply ingrained in the American spirit, to say nothing of pervasive distrust of government processes. Moreover, some health policy experts have argued for encouraging competing practice guidelines as a way of contractually reforming the health care system (Havighurst 1991: 93).

Accepting that there will almost certainly be multiple guidelines for many conditions, courts will have to engage in a process of deciding, when guidelines conflict on a material point, which one to treat as authoritative, or more authoritative. This promises to be a daunting task. As shown by the breast cancer screening example presented earlier in this article, knowledgeable, respected professional groups can, and often do, come down on opposite sides on a particular treatment issue. What should be done when that happens? When two (or more) groups, and thus their guidelines, are of equal stature and authority, a jury could be instructed that the defendant physician acted acceptably if he or she followed either guideline. Such an instruction would closely mirror the "two schools of thought" doctrine long recognized in numerous U.S. jurisdictions (Furrow et al. 1997: 200 n. 3). It is closely related in concept and application to the "respectable minority" doctrine discussed above.

But what if the trial judge does not view the conflicting guidelines as being of roughly similar stature or authority? What if there is a significant difference between the apparent quality of the guidelines or between the auspices from which the conflicting guidelines emanate? Should the court then exclude the guideline of the lesser organization, or instruct the jury to give greater weight to the treatment recommendations of the better known or more respected organization? That hardly seems workable; arguably it even violates due process by invading the province of the jury. 
What is likely to happen, then, is that, assuming both guidelines meet minimum qualifications, they will both be admitted and the jury will be left to choose between them - perhaps with adequate wisdom, perhaps not. If the court regards one of the guidelines as not meeting the minimum standard for admissibility, presumably it could and would exclude it; but what criteria would it use in making that determination? If these questions seem familiar, perhaps it is because they are issues raised by the implementation of the Daubert decision, discussed by Shuman here. Surely, a means to help courts sort out the problems posed by conflicting guidelines would be a major contribution to the utility of guidelines and the willingness of courts to deal with them. A governmental certification program for clinical practice guidelines would seem to offer substantial benefits in this regard. Before proceeding to lay out such a legislative solution, however, it would be well to examine the underlying "politics" of CPGs.

\section{The "Politics" of Clinical Practice Guidelines}

As some commentators have recognized, the development and promotion of EBM has important political dimensions. The rapidly evolving science of outcomes assessment and its expanding application to the everyday delivery of health care have the potential to change substantially the dynamics and power relationships in the health care provider community, affecting the prestige and pocketbooks of powerful vested interests. Not surprisingly, there is an inherent cultural (some would call it "political") conflict between those who support EBM and those who support continuance of the traditional regime in which individual physicians' subjective and independent judgment holds sway. The ripples from this culture clash extend beyond health care practice and will surely influence how the law deals with medical evidence. The cultural/political dimension merits consideration here; and, in this regard, three additions to the literature in the 1990s offer useful insights. Consideration of these insights, interesting in their own right, will also inform our later exploration of the advisability and feasibility of a guidelines certification program.

\section{Knowing and Acting in Medical Practice}

Sandra Tanenbaum's 1994 article, "Knowing and Acting in Medical Practice: The Epistemological Politics of Outcomes Research," describes the 
results of a small-scale study she conducted in a department of internal medicine to discover how physicians reason about clinical care, learn from their experiences and other information available to them, and pass their knowledge on to their professional colleagues. Her study gives valuable indications as to whether physicians are likely to "buy into" outcomes research and let its results influence their diagnostic and therapeutic decision making. She observes that, at a basic level, physicians have two very different ways of processing information: "At the level of clinical practice, realism and empiricism represent two approaches to medical problem solving: deterministic and probabilistic. Deterministic reasoning searches out mechanisms of illness and therapy, including etiology, pathophysiology, and the mechanisms of action. Probabilistic reasoning draws on what past experience predicts, whatever the cause. The probabilist plays the odds while the determinist imagines the process" (Tanenbaum 1994: 30-31).

Tanenbaum goes on to analyze the various ways physicians make sense of what they experience in their clinical practice. She notes that they tell "interpretive stories" about their cases, using a deductive reasoning process to distill their experiences into values that guide their future treatment of patients and are passed on to their colleagues in ways both informal (e.g., lunchroom conversations) and formal (e.g., grand rounds, conference presentations, journal articles, etc.). Through these processes, "Every doctor accumulates a vast and idiosyncratic knowledge of medicine" (ibid.: 33, emphasis supplied). From these and several other perceptive and intriguing observations, she concludes that physicians' decisions are not likely to be greatly influenced by outcomes research. They are inclined to be distrustful of outcomes research studies and the conclusions drawn from them. Moreover, even when they accept that the research findings are accurate in general, they tend to find reasons to believe that their particular patient is atypical and, therefore, merits treatment different from that which might normally be indicated by the study results. To put it perhaps too simply, given the detail and subtlety of her analysis, doctors are strongly inclined to hold to their idiosyncratic views, even in the face of strong contrary research evidence. "The clinical medicine I observed was essentially interpretive and therefore irreducible to probabilities, no matter how rigorously derived" (ibid.: 31). Tanenbaum's analysis lays an important foundation for Gary Belkin's (1997) and Matthews's (1999) observations regarding doctors' skepticism about the kind of information that forms the core of evidencebased medicine. 


\section{The Technocratic Wish}

Belkin's article "The Technocratic Wish: Making Sense and Finding Power in the 'Managed' Medical Marketplace" (1997: 509) discusses the "technocratic wish," which Belkin defines as "an appeal to objective measures to resolve contentious issues and/or clothe their resolution as scientifically logical and natural." In the arena of managed care, the technocratic wish takes the form of a search for a (seemingly, at least) objective and verifiable rationale to justify the shift of control from an entrenched medical elite to a new cadre of health services researchers, MCO executives, and government policy makers. This latter group views the country's health care needs, and thus leans toward allocating its health care resources, using a systems approach, looking at issues on a macro rather than micro level, and employing population-based rather than individual-based measures to assess the utility and cost-effectiveness of health care inputs. To put it another way, the "technocrats" tend to measure the success of health care activities by looking at their aggregate effect on populations rather than on individual patients, contrary to the clinician's natural tendency to focus on the individual patient she or he is currently treating.

To implement their health care philosophy, those who share the technocratic wish collect data from entire populations, crunch the numbers, and express their conclusions as to what works best in terms of population-wide statistics. Their methodology is more quantitative and, on the surface, at least, more objective than medicine's traditional way of assessing the effectiveness of health care, that is, by cumulating the qualitative observations of individual physicians based upon their experiences with individual patients. The first approach appears more objective, the latter more subjective, since with the latter every observation must go through an individual physician's personal, subjective filter before becoming a data point in the analysis. Belkin (ibid.: 512) points out, however, that the seemingly objective quantitative approach is vulnerable to a "subjectivity of objectivity." In other words, researchers necessarily make choices among the many different ways of constructing scientific tests and measures and of interpreting and framing the results. When the range of possible approaches is recognized, it can be seen that analysis that appears to be objective and inevitable actually is a mosaic of subjective choices. Thus the difference in objectivity between the new approach and the traditional approach may not be as great as devotees of the technocratic wish would have us believe. 
In Belkin's view, managed care has embraced the technocratic wish in its desire to find a rationale and a mechanism for standardizing medical practice and reining in physicians' natural inclination to treat each patient as a special case. MCOs, health insurers, and federal health programs commonly seek to control, or at least guide, how physicians treat patients by pointing to the results of outcomes research and asserting that, by and large, this should determine what care is provided and how. This approach obviously runs counter to the natural tendencies of physicians described by Tanenbaum. Belkin's analysis bears on our present discussion by helping to address the question of how influential customary professional practice should be in setting standards for measuring physician performance when the application of EBM methodologies would point in a different direction. In other words, how much weight should EBM be given when it comes into conflict with the traditional dynamic of subjective judgment and physician autonomy-either the autonomy of individual physicians or the collective autonomy of professional groups?

Practice Guidelines and Tort Reform. Building on Belkin's analysis, Matthews's response, "Practice Guidelines and Tort Reform: The Legal System Confronts the Technocratic Wish" (1999), describes the battle for control of the health care system as one that pits the qualitatively oriented clinician - the "artful practitioner," as Matthews terms heragainst the quantitatively oriented scientist. Operationally, the contest is between the subjective judgment of individual professionals derived from and applied to case-by-case experiences and across-the-board rules distilled by health services researchers from "large $n$ " studies. It is also a contest between professional discretion and "cookbook medicine," between the "art" of medicine and cold, hard science. Tanenbaum, Belkin, and Matthews all recognize a broad distinction between hands-on clinicians and the more data-driven types who tend to be drawn into the fields of research medicine, health plan administration, and health policy formulation. The conflict between their worldviews is mirrored in the faceoff between those who practice medicine in the trenches and those who run MCOs, governmental health programs, and the federal health policy process.

As a side note, it is interesting to contrast the view of physicians put forward in these three articles by Tanenbaum, Belkin, and Matthews with that expressed by Paul Starr in his classic 1982 book, The Social Transformation of American Medicine. Among Starr's many keen insights 
is his observation - not all that profound in itself - that physicians as a group acquired their prestige and power in large part by holding themselves out as men of science. Their devotion to the systematic, scientific pursuit of truth set them apart from, and above, lesser members of society. To now look in a more detailed and precise way, using the lens of the three more recent commentators, and see physicians - at least the archetypal physicians, clinicians - cast not as scientists but rather as "artful practitioners" with a bias against the emerging science of outcomes research and EBM is, at first, surprising. Upon reflection, however, this shift reveals something we all know, namely that things look different from up close than they do from farther away or, to put it another familiar way, that "all things are relative." Clinicians may fall at the less rigorously scientific end of the physician spectrum, according to Tanenbaum, Belkin, and Matthews; but don't forget that the spectrum in question is an array of scientifically oriented professionals. Therefore, it is possible, and mostly accurate, to regard physicians on the whole as people of science while, at the same time, noting vast differences among this group in terms of their approach to science. Just as in George Orwell's Animal Farm some pigs were "more equal than others," so in the world of medical science some physicians are "more scientific" than others.

Turning back to the difference of perspectives between medical practitioners and those who run health plans and participate in the policy process, it is apparent that this parallax reflects, and magnifies, the underlying tension between doing the best for individual patients and making the right systemic allocation choices for patients as a whole in what is essentially a zero-sum game. The Benthamesque (social utilitarian) goal of trying to achieve the greatest good for the greatest number is often in conflict with the goal of trying to serve individual patients unreservedly and rendering the best (although it is often the most expensive) care for the individual without regard to the longer-term systemic consequences.

Matthews's article extends Belkin's thesis by examining how the courts' treatment of CPGs can be expected to affect their adoption and use by the medical community. His analysis supports the view, expressed above, that allowing the use of CPGs only for defense purposes, as in Maine and Minnesota,- - was a political decision meant to stimulate the adoption and use of guidelines by a physician community otherwise reluctant to accept them, in part because of its fear of the liability consequences. Getting physicians to rely upon and conform their practice to 
guidelines based on quantitative, empirical, outcomes research is challenging. Even more challenging is getting them to acknowledge this reliance in a formal courtroom setting. As Matthews (1999: 287) observes, for "most of the twentieth century, the legal system has validated the medical profession's belief that the authority of clinical judgment derived from personally acquired disciplinary expertise." For that reason, permitting physicians to introduce evidence that they followed practice guidelines is "not merely a technical change in the law; rather, it is using the regulatory function of law to facilitate the health economists' construction of authoritative medical judgment based on the ideal of impersonal and standardized objectivity, that is, the technocratic wish" (ibid.).

It is interesting to note that in speaking of the "regulatory function of law," Matthews posits that law has two broad functions: litigation, the settlement of disputes, which is retrospective (backward-looking) in orientation, and regulation, which is prospective (forward-looking). The law's regulatory function is much more compatible with the notion of EBM, which casts things in probabilistic terms. Regulation, which looks to the future, necessarily deals with what might happen, a probabilistic notion, rather than trying to determine what actually did happen in a past incident, the obvious focus in litigation. Since our focus here is on how courts will deal with CPGs in a litigation situation, the tension between the essentially probabilistic nature of EBM evidence and the deterministic requirements of assessing and assigning responsibility for a past event is at its greatest — or so Matthews might argue.

Matthews's analysis addresses the factors that will dispose physicians to use CPGs in litigation; but what about the factors that will dispose courts to embrace them? Obviously, a court will admit CPGs as evidence and use them in a particular way if directed to do so by the legislature; but in the absence of a legislative mandate, what will courts be disposed to do? Just as the medical profession is accustomed to relying on the subjective opinions of physicians, courts have a long tradition of relying on the testimony of medical experts to establish what is professional custom, which, in turn, sets the legally required standard of care for the case at bar. It is intriguing to ponder possible parallels between the opposing mind-sets of the two groups described in the Belkin and Matthews articles and the mind-set of judges who will be called upon (still assuming the absence of a legislative command) to decide how to treat CPGs when they are offered as evidence. Presumably the reason that the law decided many years ago to use professional custom as the basis for setting the 
legal standard of care, was that courts had no way to know what was the proper treatment for a patient in a particular instance. The obvious solution was to look to the medical profession and assume that what it customarily did was the right thing to do. Today, a judge might be faced in such an instance with two proffers of conflicting evidence: one the traditional proffer of an expert witness who would testify how the profession commonly treats such a case, the other a practice guideline proffered to show the current EBM-based judgment as to what treatment works best in such a case. How would the judge likely rule on the admissibility of the latter type of evidence? If the evidence were admitted, how would the judge likely instruct the jury to treat it? These questions recall earlier discussion as to the various ways CPGs might be treated by the courts. However, the question here is not just what treatments are possible but, rather, what would the court most likely be disposed to do?

One might answer, simply, that the court would do whatever legal precedents require it to do. But, as Matthews's (1999: 288-294) discussion of a group of cases involving guidelines reveals, courts are not so constrained by precedent that they have no choice in this matter; and courts have gone in different ways when presented with that choice. As Matthews (ibid.: 289) puts it, "Regardless of which party in the dispute introduced the guideline, however, the litigation always casts the same issues into especially bold relief: the conflict between the impersonal objectivity of a guideline and the personalized expertise of the physician, or the conflict between the guideline's focus on general decision procedures and the legal (and medical) profession's focus on the particular facts of the case under consideration."

Might not judges in general be more disposed to rely on medical expert testimony than on the more technocratic input, the guidelines? Given its emphasis on precedent (past decisions), the legal system is inherently conservative and backward-looking. Therefore, since reliance on expert testimony is the long-established norm, change can be expected to come slowly. Moreover, law is much more a qualitative (verbal) than a quantitative discipline; judges might be less comfortable relying, or instructing a jury to rely, on a guideline derived from quantitative, statistical processes rather than on expert witnesses' "interpretive stories." On the other hand, in the post-Daubert era, as Shuman articulates, federal judges have a duty to ensure that juries are presented with scientific evidence that is enlightening and not confounding. Even state court judges, who are not directly touched by the Daubert ruling - except in those states that have opted to follow Daubert - may feel more inclined than previ- 
ously to direct juries toward standard-of-care evidence that is more definitive, authoritative, and clear.

Does this mean that judges will favor the use of guidelines over the testimony of expert witnesses? Not necessarily. This is currently an area for speculation because, despite the academic work done to ferret it out, there is scant evidence to date of how judges will react to this new form of medical evidence. The only thing safe to say is that we cannot assume courts, left to their own choice, will move toward greater use of CPGs. If we want CPGs, and EBM generally, to have greater prominence in the courts, legislative action is needed. Maine, Minnesota, Kentucky, Florida, and a handful of other states have spoken, albeit not that fully and clearly, on the subject of guidelines. Most states, though, have not yet taken a position. This commentator, for one, believes that they should, but with federal leadership. EBM approaches, including the development and use of CPGs, are a better way of guiding the practice and progress of medicine. The nation's courts should be opened to the evidentiary use of guidelines. If it takes legislation to assure that this will come to pass in a timely fashion, a focused effort to promote such legislation seems the right prescription.

\section{The Implications of the Political Terrain}

The following section proposes a certification program for CPGs. How does the "political" terrain described above bear on the feasibility of such a program? Some general observations can be made, and, frankly, they offer little encouragement. If physicians are not disposed to accept the notion of CPGs in general, they are not likely to welcome a proposal to give guidelines a federal imprimatur and increased importance in the courts, moves intended to stimulate greater development and adoption of guidelines. In short, the terrain is not-at first glance, at least-all that favorable. Let's examine that terrain, though, as an architect might do in considering what kind of house, if any, can be built upon a difficult piece of land. Sometimes, as in the case of Frank Lloyd Wright's Fallingwater, a very serviceable and impressive edifice can be constructed on seemingly inhospitable real estate.

If, as Tanenbaum observes, clinicians are inclined to distrust the science underlying outcomes research, EBM, and CPGs, or to discount their relevance to individual practice situations, and if, as Belkin and Matthews contend, guidelines are largely seen as a mechanism for nonclinicians to use in controlling clinicians, a guidelines certification proposal can expect 
a tough, uphill climb to passage. Three questions will help to measure the steepness of the ascent. First, can physicians be brought to understand that they have more to gain than to dread from CPG certification? Second, how much political muscle can the clinician population exert against the program's passage? And third, where are the other political players in this contest likely to come down on guidelines certification?

In trying to identify the various political forces at work here and to predict how they will react to a guidelines certification program, one of Paul Starr's early articles comes to mind. Long before his defining work, The Social Transformation of American Medicine (1982), Starr recognized the interplay of professional, business, and public interests that sets the stage for legislative action. In "Malpractice: The Doctor's Discomfort," published in the New Republic in 1975, he explained how, and why, physicians and other health care providers, liability insurers, the legal profession, and the general public would position themselves around the countless legislative programs being put forward to correct the so-called medical malpractice crisis of the 1970s. His words, although addressed to a somewhat different issue, seem just as apt in the present context:

A crisis of any kind is a moment of potential discontinuity in social affairs, simultaneously a danger and an opportunity: a danger to the orderly operation of a social system but also an opportunity for those who wish to change it in some way. For this reason, crises are not always resisted; on the contrary, they are often welcomed. A crisis can be a truly marvelous mechanism for the withdrawal or suspension of established rights, and the acquisition and legitimization of new privileges. The power to create crises (and the opportunities they bring) and, just as important, the power to define them are not distributed equally in society. Some groups are better positioned than others to promote their conception of events and to enlarge their discomforts into social concerns. This is the case with the malpractice crisis. It is the malpractice problems of physicians and insurers, rather than those of patients, that now constitute a crisis. This is a reflection not so much of the relative seriousness of their difficulties as of their relative power to turn private into public troubles.

These two groups, the physicians and insurers, along with the legal profession, dominate the current situation. Within this triad, all the terms of debate are set. Whatever the resolution of the current crisis, it will almost certainly have to satisfy the interests of the three dominant parties. Less certainly will it have to satisfy the interests of the public. The public has no clear conception of what its interests are, 
whereas the three dominant parties most emphatically do. (Starr 1975: 17)

The players are somewhat different in the current context from that described above, but physicians are still squarely in the middle. Their voice is powerful and is heard not only from their own mouths but from those of their patients, who still, even in this age of diminished physician dominance, derive much of their view of the health care system from talking to their physicians. The current "backlash against managed care," which has political reverberations all the way up from the local to the presidential level, is substantially driven by physicians interpreting to their patients what is happening on the health care scene. If physicians feel threatened by the guidelines movement, they will see to it that their patients perceive it as a threat to them as well. "Cookbook medicine," especially if its recipes are being written by "the folks who brought you managed care" and endorsed by "big government," can easily be made to seem very threatening to the general public. The chief lesson from all this is simple and straightforward: physicians' opinions matter. If they are to throw their weight behind a guidelines program — not just to pass it but to embrace it in the ongoing fashion needed to make it work - they will have to be courted. The courting, however, should not take the constitutionally and ethically questionable form of "one-way street" legislation that allows use of guidelines only by and for the defense. It should, and must, be based substantially on education. Physicians must be shown how guidelines can work in their favor, not just against it, as they are inclined to believe currently.

\section{A Certification Program for Clinical Practice Guidelines?}

In a 1995 article, I floated as a "trial balloon" the possibility of establishing a federal program for certifying clinical practice guidelines (Rosoff 1995: 394). Now, five years later, the idea still appeals to me as a good way of spurring the development and acceptance of high-quality guidelines and of aiding the courts in making determinations involving quality-of-care and entitlement-to-benefits issues. As the use of CPGs continues to grow, courts will inevitably encounter them in proffers of proof by one or both sides in health care lawsuits. Except in the few states (e.g., Maine, Minnesota, and Florida, to name the most prominent) that have enacted legislation on the subject, judges will have no guidance on how to deal with them. As in past instances of case-by-case doctrinal devel- 
opment, they will cast about to find the right approach; and, presumably, they will eventually devise workable rules. However, the time, effort, and other costs of having this process be one of uncoordinated activity in the state courts are hard to justify. A CPG certification program, coupled with some direction to courts as to how to handle both certified and uncertified guidelines, could surely reduce the valuable resources that might otherwise be expended in this process - to say nothing of the false starts and mistakes, and possible injustices to litigants, along the way.

What is needed is a governmental certification program to give guidance to the courts in two main dimensions: first, in distinguishing guidelines entitled to full credibility and weight from those not as deserving and, second, in deciding what evidentiary weight to accord guidelines falling into each of these categories. One thing should be made clear at the outset: this proposal does not intend to be prescriptive about medical practice. It contemplates that there can, and should, and will, be multiple guidelines for given conditions. Any body (or anybody; in theory, it could be an individual as well as an entity) that wants to submit a guideline for certification may do so. The result envisioned would be a freemarket competition in guidelines, but with a governmental "seal of approval" that makes it easy to identify a valid guideline. It would be possible for multiple, conflicting guidelines to be certified; and uncertified guidelines would have their place too, albeit a much less favored place. The program would not, I repeat, have government decree how patients should be treated or limit the advance of medical knowledge by enshrining the current state of practice in a bureaucratic orthodoxy. Nor would the program increase the exposure of physicians and other healthcare providers to litigation. To the contrary, it would lessen the need for litigation and, when litigation does occur, it would make it simpler, more efficient, and less costly. Notwithstanding that, in my view, the program's benefits would substantially outweigh its costs, I am under no delusion that it will meet with ready acceptance. Numerous issues and objections can be raised and inevitably will be. The more obvious and important of these are identified and addressed below.

\section{Basic Concept and Operation of the Certification Program}

Stated most simply, the proposal described more fully below calls for the establishment of a federal certification program for clinical practice guidelines, operated out of the Department of Health and Human Ser- 
vices (HHS), presumably by the Agency for Healthcare Research and Quality (AHRQ). The agency running the program would have responsibility for vetting, certifying, supervising periodic updating, and helping to promote the dissemination and adoption of CPGs. The program would be voluntary and open to any person or entity wishing to put a guideline, or set of guidelines, forward for certification. Basic, fixed costs of running the program would be funded through the federal budget; variable costs would be covered through fees charged to those submitting guidelines for review. The process of certification would involve not just government personnel but also representatives of the provider and consumer communities. Certification, the federal "seal of approval," would give a guideline greater credibility, making it more "saleable" in the health care marketplace and would also entitle it to special treatment in federal and/or state courts in litigation involving quality-of-care and entitlementto-benefits, or coverage, claims. Essentially, a certified guideline would be accepted by the courts as setting the legal standard for acceptable quality of care in a malpractice suit, or for determining in a coverage dispute whether a given treatment was medically appropriate. Since fixing the applicable standard of care is a core issue in most malpractice and coverage litigation, providing a simpler way to resolve this issue would significantly streamline the litigation process, saving time and money for all involved.

\section{Who Should Do the Certifying?}

Certification of guidelines could be done on the private or public level and, if on the latter, by either a state or a federal agency. The last of these alternatives clearly seems to be the best. Accreditation programs run by nongovernmental entities - such as the National Commission on Quality Assurance (NCQA), which accredits managed care organizations, and the Joint Commission on the Accreditation of Healthcare Organizations (JCAHO), which accredits hospitals and other institutional providershave been used as adjuncts to governmental regulation for many years and have a commendable track record. However, although the success of entities such as NCQA and JCAHO shows that private organizations can contribute importantly to the definition and safeguarding of the quality of care, because the proposed CPG program contemplates application of its output in the courts, it is simpler and more certain to have a single, governmental agency setting and implementing the standards for certification. The main purpose of certifying guidelines is to help courts distin- 
guish those that are valid and credible from those that are of questionable merit. Having a single, official certification process best supports this objective; having multiple certification processes and standards would reintroduce complexity and uncertainty into the situation and would thus be counterproductive.

Assuming, then, that a government certification program is the preferred approach, should the process be handled at the state or federal level? Some have advocated state programs over a federal program, at least as an initial step (Trail and Allen 1995-96: 250). However, even though a few states, such as Maine, have taken on the burdens of certifying guidelines (24 Maine Revised Statutes Annotated, Section 2973), the task ultimately is too large and complex to be administered effectively at the state level. To handle not just the initial certification of guidelines but also periodic updating to recognize and incorporate advances in scientific knowledge and medical practice, there would have to be a highly skilled core staff for whom review of guidelines was their main activity. Maintaining consistently high-quality certifying agencies at the level of the several states would be problematic. Furthermore, the waste and redundancy inherent in duplicating certification activities in the states, increasing cost not just for the states but also for guidelines issuers and users, many of which are national in scope, makes a state-level process highly undesirable. Finally, with a state-level process would come the possibility that a guideline certified in one state might be disapproved in another, opening the door to the very kind of sorting-out confusion the certification program is intended to avoid. Despite the obvious negatives to state-level certification, states would still be allowed to engage in this activity if they so chose; in fact, it is hard to conceive how they could be barred from doing so. It is unlikely, however, that many states would choose to undertake this complex, labor-intensive, and expensive activity if a federal program were in place. If some states did, they would at least have the federal model to look to for guidance.

Assuming that a federal-level program is the way to go, an existing entity, AHRQ, a unit within the HHS, is the obvious choice to perform the guideline-certifying function. This choice acknowledges AHRQ's core mission and its substantial contributions over more than a decadelargely under its former name, the Agency for Health Care Policy and Research (AHCPR) — toward developing and refining the methodology for generating CPGs. It also recognizes AHRQ's recent efforts, with ECRI (known in the 1960s as the Emergency Care Research Institute), a nonprofit healthcare research organization based in suburban Philadel- 
phia, to compile and maintain an extensive on-line database of practice guidelines, the National Guidelines Clearinghouse (NGC). ${ }^{3}$ In fact, a Web-accessible database like the NGC, and the organizational infrastructure to support it, is a sine qua non for a workable certification program, further confirming the appropriateness of looking to AHRQ.

It should be clearly understood that, while AHRQ would provide leadership and technical assistance in the development of guidelines, and would work closely with CPG developers, it would not develop guidelines on its own. Private-sector activities supporting the development of CPGs should be encouraged and relied upon to the fullest extent practicable. Moreover, nongovernmental parties representing professional interests and the health care-consuming public should be involved in the review of guidelines. The government's role in defining standards for medical practice should not extend beyond what is necessary to assure the safe and sensible development and application of CPGs.

\section{Should Certification Be Mandatory or Voluntary?}

The guidelines certification program should be voluntary. In fact, it is hard to imagine how a mandatory program would work. The FDA (Food and Drug Administration) process for reviewing the safety and efficacy of drugs is mandatory, in that no manufacturer is allowed to market drugs that have not been approved. But given the pervasiveness of guidelines and the infinite number of forms they can take, it would hardly be possible to say that no guidelines can be used unless approved by the government. In a voluntary program, the decision to seek certification of a CPG would rest entirely with its issuer, as is presently the case when a guidelines issuer elects to submit its CPG for inclusion in the NGC database. The incentive to seek certification would be great, however, as there would be benefits to having one's CPG certified, especially with regard to the way certified guidelines are treated in the courts. As discussed below, courts would be directed by legislation to treat certified CPGs as setting the applicable standard of care in cases involving quality of care or coverage under health plans.

3. For further information on NGC activity and a firsthand look at its work product, visit www.guidelines.gov. For background on the ECRI, visit www.ecri.org. 


\section{The Criteria for Certification}

To be certified, a CPG would have to be developed: (1) through rigorous, scientific outcomes research, based upon an appropriate and adequately large set of clinical practice data; (2) using appropriate methodology, as defined by AHRQ regulations; (3) with input from qualified medical professionals; and (4) with provision for frequent updating, to incorporate advances in medical knowledge generally as well as experience gained through clinical practice using that particular CPG. Guidelines developers would be required to maintain an efficient system for the ongoing monitoring and evaluation of experience with the clinical use of their guidelines. This would be similar, in concept at least, to the mechanism by which the FDA requires pharmaceutical manufacturers to track clinical experience with their newly approved drugs.

A further requirement for certification would be that the guidelines must be well written; they must be sufficiently clear and easy to follow that clinicians and others seeking to use them can do so confidently and safely. Just as there is a science to developing the content of CPGs, there is an art to expressing that content coherently. Here the expertise of AHRQ would necessarily be brought to bear; a guideline that the reviewers could not understand would hardly pass muster.

\section{The Significance of Certification}

Certification of a guideline would offer a number of benefits to its developer and to those who used it. First, the credibility bestowed by the governmental imprimatur, an assurance that the guideline was properly developed and well expressed, would assist the developer in getting people to adopt it. If the guideline were being developed for sale - for example, by an outcomes research organization that used EBM methodologies to write cost-containing guidelines for use by MCOs - the developer could command a better price for a certified guideline, in large part because of the way courts would treat a certified CPG as compared with one not certified. A certified guideline would be admissible in court as evidence of the appropriate standard of care without further proof of validity. Moreover, compliance with a certified guideline would raise a presumption of proper care.

To offer a concrete example, suppose an HMO were to disseminate to its participating physicians a guideline that called on them to use more sparingly an expensive test that previously had been in routine and frequent use. Assume that this cost-reducing guideline was based on 
recently completed outcomes research that showed that conventional, more liberal use of this test wasted resources without yielding a discernible benefit in terms of patient outcomes. The HMO could gain a significant cost-competitive advantage by promoting less frequent use of the test, but its participating physicians might well be concerned that if one of them happened to experience a bad result apparently associated with departure from standard practice, the physician's deviation from the professional community standard of practice would expose him or her to malpractice liability. The court's direction to regard compliance with a certified guideline as proof-either conclusive or rebuttable proof that the care rendered was adequate and thus not tortious - would be a powerful counterforce to the physician's reluctance, on legal grounds, to depart from traditional overuse of the test. This hypothetical example reflects, by the way, a fundamental, recognized purpose of CPGs, to help overcome the resource-wasting phenomenon of "defensive practice of medicine" (Daly 1995).

As to whether compliance with a certified guideline should raise a conclusive or a rebuttable presumption of adequate care, arguments can be made for either position. A conclusive presumption would effectively give certified guidelines the force of law and would be the simpler approach. Proof of compliance - or proof of noncompliance if the guideline were being used by the plaintiff for inculpatory, or "sword," purposes - would end the inquiry as to the adequacy of the care given. This approach seems too pat, however; and cases could arise in which justice would demand further consideration. For example, suppose a patient suffered harm when her physician followed a certified guideline that, it could be proven, he knew was rendered arguably obsolete by recent scientific findings but that he chose to follow anyway. (Assume, for example, that a new guideline had been certified, as the defendant knew, but the old guideline had not yet been retired.) Allowing compliance with the older certified guideline to shield the defendant's actions completely would tend to chill the advance of medical knowledge, an acknowledged danger of certification processes generally. Rebuttal of the presumption of adequate care should be allowed, but should not be too easy, or else it would undermine excessively the value of certification. A reasonable middle position - perhaps along the lines of Senator Chafee's 1993 health care reform proposal mentioned above-would be to let the presumption be rebutted but only by "clear and convincing evidence." This recognized standard of proof lies between the traditional civil standard of "preponderance of the evidence" and the much stricter criminal standard of proof "beyond a reasonable doubt." 
Unlike the Maine and Minnesota guidelines programs described above, the proposed program would treat evenhandedly the parties to litigation implicating CPGs. Plaintiffs should be allowed to use certified CPGs on the same basis as defendants, eschewing the Maine/Minnesota "shield-only" or "one-way street" approach. While CPGs may be more useful to one party than the other in some circumstances, access to their use and the basic procedural and evidentiary rules should be the same for both. One important reservation to this principle should be noted, however: the presumption of proper care should prevail. Where two (or more) certified guidelines were in conflict, with the plaintiff asserting noncompliance with one ("sword" use) and the defendant relying upon compliance with the other ("shield" use), the presumption that the defendant's care was adequate should be upheld. If the defendant health care provider could show compliance with an appropriate, certified guideline, he or she would be entitled to the presumption that the treatment rendered was adequate to meet the legal standard of care, even in the face of a contrary, certified guideline proffered by the plaintiff-patient. To apply this to the breast cancer screening example above, if both the National Cancer Institute's guideline calling for biennial breast cancer screening for women in a given age and risk category and the American Cancer Society's guideline recommending annual screening for this same population were certified, the provider, the HMO in this case, would prevail. Such treatment would be the functional equivalent of the "respectable minority" doctrine currently applied in many U.S. jurisdictions.

Note that, while this approach would greatly simplify the court's job of determining what standard of care to apply and would give the defendant provider an important "benefit of the doubt," it would neither answer all questions nor assure the defendant of victory. In many cases, an important issue might remain as to whether the guideline(s) proffered was (were) appropriate to the facts at hand. No matter how much benefit of the doubt was given to a particular CPG, it would not carry the day unless it was found to be an appropriate guideline for the situation at bar. Likewise, there might be substantial factual dispute as to whether the guideline was, in fact, followed by the defendant and, if it was not, whether the harm suffered by the plaintiff was caused by the defendant's noncompliance. The only thing changed by the guidelines certification program would be the simplifying of the court's search for the proper standard of care to apply; but that one change would be a most significant contribution to the cause of judicial efficiency.

What treatment should be accorded to an uncertified guideline under 
this regime? This is a tricky question that deserves closer consideration and debate before a firm position is taken. As a starting point, it seems clear enough that a court should be able, in its discretion, to admit an uncertified guideline into evidence if satisfied that the guideline meets the criteria for validity specified in the certification program. Presumably, courts would generally be disinclined to engage in such an inquiry; and issuers and users of guidelines would be motivated to undertake certification to avoid the uncertainty of not knowing how a given court would react to their uncertified guideline. On the further question of what weight and treatment to give certified as opposed to uncertified guidelines, things are less clear. Putting uncertified guidelines on substantial parity with certified ones would undermine the incentive to seek certification; however, discounting their evidentiary value too greatly would belie the claim that the certification program is voluntary. Numerous lesser questions can be raised. For example, if an uncertified guideline is admitted, should the court allow inquiry into why it is uncertified? Is it because the developer did not seek certification, or was it sought and denied? Should the court allow the jury to be led through an exploration of why it was denied? These are subtle questions indeed. In addressing them, policy makers should keep in mind that a main purpose of promoting the use of guidelines in the courts is to simplify and rationalize the litigation process, not to add new and uncharted dimensions of complexity.

One final, but very significant, point should be noted about the implications of certification. The developer and/or issuer of a CPG should be immune from civil liability for harms caused by its adoption and use if the requirements for certification have been met. This would seem to follow logically and implicitly from the foundation principle that compliance with a certified guideline shields the user of the guideline; but the implication for the guideline developer/issuer should be explicitly acknowledged. Although it is unclear whether guidelines issuers might be liable under current law, there has been scholarly speculation on the issue (see e.g., Brennan 1991: 78-81; Rosoff 1995: 91-93), and the possibility is real enough to provide additional motivation to issuers to seek certification.

\section{The Costs of a Certification Program}

The proposal is simple to state on this point: general costs related to AHRQ's activities as the certifying agency should be borne by the federal budget. Reasonable costs of initial certification, and of periodic recertifi- 
cation, should be borne by the entity issuing the CPG. This approach roughly follows that used by the FDA in its approval process for drugs and medical devices; and there is ample precedent to be found in other federal regulatory programs as well. A more detailed analysis of the likely costs of a federal guidelines certification program with both the onbudget and off-budget costs is beyond the scope of this essay but would, of course, be an important consideration in any legislative debate about adopting such a program.

\section{The Challenges of Implementation}

The guidelines certification program proposed here poses a number of challenging issues, not the least of which is the daunting task of gaining sufficient support within the administration and in the Congress to have it put forward and enacted. Without meaning to minimize that concern, the simple answer is that it is beyond the scope of this essay. In any event, unless some consensus can be developed that a certification program of the type proposed is worth having, there is little point in strategizing about how to get it passed.

Assuming adequate political support for a certification program of the type envisioned, a central question is how its proposed impact on state law and state court processes would be achieved. One would hope, of course, that states would see the value of the certification program and would want to support it through their court systems without any compulsion. If this were not the case, at least with particular states, other means of attaining state participation would have to be sought. This is certainly not a trivial problem. While a full treatment of this issue would extend the article well beyond the constraints of this symposium, it would be cavalier not to address it, at a basic level at least.

Both the provision of health care and the operation of the insured and employer-self-funded plans that pay for much of it are so intertwined with interstate commerce that Congress likely has the jurisdiction to regulate it under the commerce power of Article 1, Section 8, of the Constitution. Regulation of health care-related litigation at the state level, however, implicates state sovereignty concerns in a way that regulation of health care alone does not. ERISA, the Employee Retirement Income Security Act of 1974, provides a highly visible precedent for federal preemption of state law in this area, although, in the view of many commentators, it is not a particularly positive precedent (see, e.g., Mariner 1996, 2000). If implementation of the state law aspects under the federal 
Commerce Power is deemed too problematic, there is also the possibility of using the Spending Power, also under Article 1, Section 8. States could be offered financial incentives for voluntarily participating in the program, much as federal highway funding was tied in the 1970s to states' adoption and enforcement of the 55-mile-per-hour speed limit. Finally, the certification program could be tied to other federal health care programs, principally Medicare and Medicaid, loosely following the precedent established by the Emergency Medical Treatment and Active Labor Act of 1985 (EMTALA), which requires hospitals participating in Medicare to provide urgent care to all of their patients, not just those with Medicare coverage. There are numerous other examples of federal health care initiatives being successfully implemented at the state level either through the Commerce Power (e.g., the 1974 Health Care Amendments to the National Labor Relations Act, Pub. Law 93-360, codified in Section 152 of Chapter 42 of the U.S. Code) or an artful use of "carrot and stick" mechanisms (e.g., the National Health Planning and Resources Development Act of 1975, Pub. Law 93-641, 42 U.S. Code, Section 300K et seq.). Given this range of possibilities and precedents, it is fairly certain that the jurisdictional premises upon which the program rests can be successfully handled.

Assuming the program can be enacted, an important ongoing concern is that the certification process not be allowed to freeze, or even chill, the advance of medical knowledge and practice. This issue has been touched on above and is not easily resolved. The program, as implemented, must provide a prompt, efficient, and low-cost process not just for the review of new guidelines but also for the timely updating and revision of approved guidelines, including the decertification of guidelines known to be no longer valid. There must be adequate budget to assure an ample number of competent reviewers and an ongoing commitment to rapid turnaround of materials submitted. The use of electronic submission of materials and subsequent communication about them should be a significant help in this regard.

\section{Conclusion}

Proposals for federal certification of clinical practice guidelines, including not only my own freestanding proposal but also those contained in the Clinton, Chafee, and other federal health care reform proposals, have been "around" for over five years without attracting substantial attention or support. This is true despite the growing acceptance and use of CPGs 
during this period. If anything, the continuing proliferation of CPGs makes it more advisable that some mechanism be devised to introduce guidelines more prominently into the legal process and help courts decide which guidelines should be regarded as authoritative. I hope this present restatement and more detailed reexamination of my proposal in the context of this larger consideration of EBM will help to raise awareness that the time for a national guidelines certification program has come-or, at least, is on its way.

If the above general principles and specific elements can be fashioned into a national framework for the certification of clinical practice guidelines and a rationalized approach to their use in the courts, I believe the expanded use of CPGs it will enable will bring substantial benefits to our health care system. While there will always be a need and a place for professional medical judgment, we should make maximum use of available empirical evidence as to what works and doesn't work, synthesizing that data into carefully analyzed, widely disseminated guidelines to assist physicians to properly apply their clinical judgment. Benefits will flow to the legal system as well, making possible more accurate, efficient, and affordable resolution of disputes about the quality and appropriateness of health care provided.

\section{References}

American Medical Association. 1993. Statement to the Subcommittee on Health, Committee on Ways and Means, 103d Cong., 1st sess., Ser. No. 103-123.

Angell, M. 1997. Science on Trial: The Clash of Medical Evidence and the Law in the Breast Implant Case. New York: W. W. Norton.

Begel, J. 1995. Maine Physician Practice Guidelines: Implications for Medical Malpractice Litigation. Maine Law Review 47:69-103.

Belkin, G. 1997. The Technocratic Wish: Making Sense and Finding Power in the "Managed" Medical Marketplace. Journal of Health Politics, Policy and Law 22:509-532.

Brennan, T. 1991. Practice Guidelines and Malpractice Litigation: Collision or Cohesion? Journal of Health Politics, Policy and Law 16:67-85.

Carlin, P. 1980. Medical Malpractice Pre-trial Screening Panels: A Review of the Evidence, Intergovernmental Health Policy Project. Washington, DC: George Washington University.

Daly, M. 1995. Attacking Defensive Medicine through the Utilization of Practice Parameters: Panacea or Placebo for the Health Care Movement? Journal of Legal Medicine 16:101-132. 
Faigman, D. 1999. Legal Alchemy: The Use and Misuse of Science in the Law. New York: W. H. Freeman.

Felsenthal, E. 1994. Legal Beat: Doctors' Own Guidelines Hurt Them in Court. Wall Street Journal, 19 October, B1.

Field, M., and K. Lohr, eds. 1990. Clinical Practice Guidelines: Directions for a New Program 8. Washington, DC: Institute of Medicine.

Furrow, B., T. Greaney, S. Johnson, T. Jost, and R. Schwartz. 1997. Health Law. 3d ed. St. Paul, MN: West.

General Accounting Office. 1993. Medical Malpractice: Maine's Use of Practice Guidelines to Reduce Costs. GAO/HRD-94-8, at 26-27. Washington, DC: U.S. Government Printing Office.

Havighurst, C. 1991. Medical Practice Guidelines as Legal Standards Governing Physician Liability. Law and Contemporary Problems 54:87-117.

- 1990. Practice Guidelines for Medical Care: The Policy Rationale. St. Louis University Law Journal 34:777-819.

Hirshfeld, E. 1991. Should Practice Parameters Be the Standard of Care in Malpractice Litigation? Journal of the American Medical Association 266(20):2886-2891. . 1993. Use of Practice Parameters as Standards of Care and in Health Care Reform: A View from the American Medical Association. Journal on Quality Improvement 19(8):322-329.

Hyams, A., D. Shapiro, and T. Brennan. 1996. Medical Practice Guidelines in Malpractice Litigation: an Early Retrospective. Journal of Health Politics, Policy and Law 21:289-313.

Institute of Medicine. 1978. Beyond Malpractice: Compensation for Medical Injuries. Washington, DC: National Academy of Sciences.

King, J. 1975. In Search of a Standard of Care for the Medical Profession: The "Accepted Practice" Formula. Vanderbilt Law Review 28:1213-1276.

Lewin, L., and J. E. Erickson. 1989. Leadership in the Development of Practice Guidelines: The Role of the Federal Government and Others. Prepared for the PPRC's Conference on Practice Guidelines, Washington, DC, 11 October 1988, revised 24 April 1989.

Macchiaroli, J. 1990. Medical Malpractice Screening Panels: Proposed Model Legislation to Cure Judicial Ills. George Washington Law Review 58:181-260.

Maine Department of Professional and Financial Regulation. Bureau of Insurance. 1997. Interim Report on the Medical Liability Demonstration Project. Augusta, ME: Bureau of Insurance.

Maine Trial Lawyers Association. 1994. Professional Liability: Maine's Experiment with Practice Guidelines Produces Little Evidence, BNA's Health Law Reporter 753-754.

Mariner, W. 1996. Liability for Managed Care Decisions: The Employee Retirement Income Security Act (ERISA) and the Uneven Playing Field. American Journal of Public Health 86:863-869.

. 2000. What Recourse?-Liability for Managed-Care Decisions and the Employee Retirement Income Security Act. New England Journal of Medicine 343(8):592-596. 
Matthews, T. 1999. Practice Guidelines and Tort Reform: The Legal System Confronts the Technocratic Wish. Journal of Health Politics, Policy and Law 24:275-304.

Mehlman, M. 1990. Assuring the Quality of Medical Care: The Impact of Outcome Measurement and Practice Standards. Law, Medicine, and Health Care 18:368384.

Roper, W., W. Winkenwerder, G. Hackbarth, and H. Krakauer. 1988. Effectiveness in Health Care: An Initiative to Evaluate and Improve Medical Practice. New England Journal of Medicine 319:1197-1202.

Rosoff, A.1986. Arbitration as a Malpractice Resolution Alternative. Business and Health 3:37-42.

1995. The Role of Clinical Practice Guidelines in Health Care Reform. Health Matrix 5:369-396.

Sackett, D., W. Richardson, W. Rosenberg., and R. Haynes, eds. 1997. Evidence-Based Medicine: How to Practice and Teach EBM. New York: Churchill-Livingston.

Schanz, S. 1993. The Emerging Status of Practice Parameters. Medical Staff Counselor 6:31-37.

Shuman, D. 1997. The Standard of Care in Medical Malpractice Claims, Clinical Practice Guidelines, and Managed Care: Towards a Therapeutic Harmony? California Western Law Review 34:99-113.

Starr, P. 1975. Malpractice: The Doctor's Discomfort. New Republic, 28 June, 16-22. 1982. The Social Transformation of American Medicine. New York: Basic.

Tanenbaum, S. 1994. Knowing and Acting in Medical Practice: The Epistemological Politics of Outcomes Research. Journal of Health Politics, Policy and Law 19:27-44.

Trail, W., and B. Allen. 1995-96. Government Created Medical Practice Guidelines: The Opening of Pandora's Box. Journal of Law and Health 10:231-258.

U.S. Congress, Office of Technology Assessment. 1994. Identifying Health Technologies That Work: Searching for Evidence. OTA-H-608, September. Washington, DC: U.S. Government Printing Office. 